\title{
Crop root systems and rhizosphere interactions
}

\author{
Yinglong Chen 1 - Jairo A. Palta $•$ Pute Wu • \\ Kadambot H. M. Siddique
}

Received: 14 May 2019 / Accepted: 29 May 2019/Published online: 18 June 2019

(C) Springer Nature Switzerland AG 2019

Crop root systems directly interact with soil in capturing water and nutrients, and are often the primary casualties of many edaphic stresses. The essential role of the root system architecture in exploring soil zones for the acquisition of soil resources has been well documented (Gregory et al. 2009; Lynch and Brown 2012). Root system architecture is a complex three-dimensional structure, exhibiting a specific spatial and temporal configuration of root types. It is plastic and dynamic, allowing plants to respond to their environments in order to enhance acquisition of nutrients and water (Zhu et al. 2011). Understanding the mechanisms of the response of root systems to

Responsible Editor: Hans Lambers.

Y. Chen $(\bowtie) \cdot$ P. Wu

Institute of Soil and Water Conservation, Northwest A\&F

University, and Chinese Academy of Sciences, Yangling 712100

Shaanxi, China

e-mail: yinglong.chen@uwa.edu.au

Y. Chen · J. A. Palta · K. H. M. Siddique $(\bowtie)$

The UWA Institute of Agriculture, and School of Agriculture and Environment, The University of Western Australia, Perth, WA 6001, Australia

e-mail: kadambot.siddique@uwa.edu.au

J. A. Palta

CSIRO Agriculture \& Food, Private Bag No. 5, Wembley, WA 6913, Australia

\section{P. Wu}

Institute of Water Saving Agriculture In Arid Regions of China, Northwest A\&F University, Yangling 712100 Shaanxi, China edaphic stresses, such as drought and low soil fertility, and rhizosphere interactions, is critical in designing and managing plant breeding programs aiming to produce cultivars with improved resource-use efficiency and improved adaptation to edaphic stresses. As an outcome of various presentations at an International Symposium on Crop Roots and Rhizosphere Interactions (October 9-13, 2017, Yangling, China), this special issue features 18 papers highlighting the significance of root traits in genetics and breeding, adaptation to water and nutrient deficits, root trait variation and plasticity in response to agronomic practices and interaction with soil microbiome.

\section{Breeding for root traits}

Although the importance of root traits for anchorage and soil resource uptake is well recognised, consideration of root traits in crop breeding programs is far behind the study of aboveground organs (e.g. Heřmanská et al. 2015). This is mainly because the unviability of efficient methods in observing and quantifying root growth in the field (Waines and Ehdaie 2007), and relatively low heritability in root traits exhibiting plasticity with soil and environmental conditions (Siddique et al. 1990; Malamy 2005; Chen et al. 2014; Palta and Turner 2019). The historical development of root traits related to grain yield in 17 winter wheat cultivars bred for higher yields and increased resistance to foliar diseases across 60 years, showed that modern cultivars had more 
root biomass at shallow depth, but higher plasticity with depth which contributed to improved yield and adaptation to varying soil water availability (Qin et al. 2019a). A novel study reports the influence of an improvement in shoot function on root traits in soybean (Glycine max) (Li et al. 2019d). Grafting high-yielding cultivar scions increased the genetic gain for root traits of 11 soybean cultivars released from 1966 to 2006, but decreased grain yield and nutrient uptake. Findings of the uncoordinated improvement between roots and shoots also highlighted the need for alternative targets in order to enhance the improvements of both root traits in relation to nutrient-use efficiency and yield-related shoot traits in soybean.

\section{Searching for drought-resistant root traits}

Global crop production is largely hampered by drought stress, with up to $50 \%$ reduction in wheat yield as an example (Reynolds et al. 2007). In order to improve yield under drought stress, researchers have extended their search from focussing primarily on shoot-related morphological and physiological traits to also included drought-resistant root traits (Manschadi et al. 2006; Abdolshahi et al. 2015). The central question has become what type of root system traits we be searching for to increase crop drought resistance (Palta and Turner 2019). Several studies propose 'ideotype' root architecture (Steep, Cheap and Deep) for enhanced water- and nitrogen-use efficiency for high grain yields (Lynch 2013; Meister et al. 2014; Zhan et al. 2015). The traitbased approach for drought-resistant root traits requires consideration of the relationships among traits (both root and shoot traits) and not just considering the trait of interest in isolation (York et al. 2013). The viewpoint by Palta and Turner (2019) clearly demonstrate that the root system benefiting grain yield under drought depends on various conditions including precipitation (amount and distribution), soil properties (texture, depth and water-holding capacity), and root system characteristics. They showed that early vigour, osmotic adjustment, and a stay-green habit, increased root growth and water use to improve crop adaption to drought stress.

Studies on crop drought resistance are often conducted in controlled environments using small pots or rapid phenotyping platforms. A critical viewpoint paper by Turner (2019) reported that pot size and shape, soil type and watering regime, plant water relations and shoot and root function, determined the measured plant responses to water deficits, as these factors influence root growth, root distribution, water and nutrient acquisition, and root-shoot interactions. Recommendations on methodologies included in this issue provide guidance for studying the effect of water deficits on plants and for phenotyping for drought-resistance traits in pots (Turner 2019). A deep column study reported in this issue examined the difference in drought tolerance mechanisms between winter and spring wheat genotypes under varying water supply (Djanaguiraman et al. 2019). This study reported a deep root system in winter wheat and a well-branched (albeit shallow) root system with more unsaturated membrane lipids in spring wheat similarly contributed to drought resistance.

\section{Phenotyping and genotyping root traits}

Crop species and genotypes within the species differ in root system traits and in their ability to access water and nutrients Germplasm representing broader genetic diversity are now being used to probe the breadth of the root trait variability (York et al. 2013; Chen et al. 2017). However, phenotyping large sets of genotypes beyond early growth stages remains a challenge, particularly for mapping studies of quantitative trait loci (QTL) (Chen et al. 2012; Xiang et al. 2015). High-throughput phenotyping must increase in extent (large numbers of plants with greater genetic diversity) and intensity (measurement of more traits per sample) (Houle et al. 2010; York et al. 2013). Using a recently established semihydroponic phenotyping system (Chen et al. 2011), Qiao et al. (2019) has made it possible to characterise root trait variability in 174 genotypes of maize (Zea mays). This study identified potential root traits that can be used as candidate traits conferring stress tolerance. Root traits such as total root length, root length at various depths and nodal root angle can potentially serve as parameters for plant breeding programs aimed at developing cultivars with improved adaptation to adverse environments and better resource-use efficiency and higher grain yield (Qiao et al. 2019). Integrating the phenotyping for root traits and phosphorus $(\mathrm{P})$ use efficiency and QTL mapping of traits related to P-use efficiency is essential in crop improvement programs for 
enhanced P-use efficiency as reviewed by Wang et al. (2019b).

\section{Impact of intercropping and planting density on root distribution and grain yield}

Agronomic practices affect root growth, proliferation and distribution down the soil profile, which in turn influence aboveground traits and yield. The availability of soil water and nutrients alter root growth and distribution in intercropping systems (Adiku et al. 2001; Liu et al. 2015). The effects of wheat/maize intercropping on root development and water uptake under varying water conditions is reported in this issue (Ma et al. 2019). The influence of wheat cultivar mixtures on aboveground biomass and grain yield across 2 years with different rainfall was evaluated by Qin et al. (2019b). The study observed increased crop performance under waterdeficit conditions following cultivar mixtures. A study on legume-dominated maize/alfalfa (Medicago sativa) intercropping revealed that alterations in soil water balance and root morphology and distribution improved $\mathrm{P}$ acquisition and the system over-yielding was achieved via alfalfa rather than maize (Sun et al. 2019). The Presource partitioning hypothesis assumes that dissimilarity in P-acquisition traits among plant species leads to enhanced $\mathrm{P}$ uptake by crop combinations compared with their sole crops. Li et al. (2019b) tested complementarity in P-resource use, but found that plant species having dissimilar traits for $\mathrm{P}$ acquisition do not necessarily improved P uptake by crop mixture compared with their sole crops.

A combined rhizobox and field study is included, confirming the effects of planting density on root system architecture in spring barley, particularly in number of nodal roots (Hecht et al. 2019). A study by Shao et al. (2019) on the plasticity of the root system architecture in response to planting density and its influence on maize yield, showed that genotypes with medium root size, medium root-angle and more inter-row root distribution had less root-to-root competition and produced higher yield at high planting density. However, Li et al. (2019c) found that heterogeneous ammonium and $\mathrm{P}$ supply induced root competition for nutrient acquisition at high planting density resulting in lower maize yield. These findings highlight the complex belowground competition for capturing resources under varying planting densities.

\section{Interactions with rhizosphere symbiotic microbiome}

In this issue, three papers highlight the interactions and functions of root-microbiome associations taking place in the soil. Wang et al. (2019a) observed an enhanced formation of cluster roots in white lupin (Lupinus albus) as a result of nodulation under low $\mathrm{P}$ availability, but a trade-off between investment of resources in nodules and cluster roots was evidenced. Formation of cluster roots or proteoid roots (Shane and Lambers 2005; Lambers et al. 2006) and mycorrhizal symbiosis (Barea et al. 2005) are considered as two mechanisms that plants have evolved for improving P-use efficiency in P-deficient environments. Inoculation with the arbuscular mycorrhizal (AM) fungus Rhizophagus irregularis improved $\mathrm{P}$ uptake and glycyrrhizin and liquiritin accumulation in liquorice (Glycyrrhiza uralensis) plants as reported by Xie et al. (2019). This study unravelled the important role of AM symbiosis in regulating secondary metabolite biosynthesis. The paper of Li et al. (2019a) examined the role of dark septate endophytes (DSE) in promoting plant growth under drought stress. This study sheds light on the potential application of the tested DSE isolated from desert Hedysarum scoparium for agricultural and medicinal plants.

\section{Simulating root structure and function}

Due to the complexity of crop root systems and rhizosphere interactions, genetic, physiological and agronomic constraints may make it difficult to unravel belowground interactions. Functional-structural root modelling simulations allow researchers to study greater phenotypic ranges, environmental scenarios, and trait functions beyond what is possible in controlled and field studies (Dunbabin et al. 2013; York et al. 2013). Mai et al. (2019) reported the development of a 3D water and nutrient transport model of the root-soil system with explicit consideration of the root system architecture and the rhizosphere. The model complements the experimental work and computing simulations of the drying and nutrient transport in the root zone, providing a 
promising tool for simulations of larger and complex root systems (Mai et al. 2019).

Root systems possess numerous traits and essential adaptive functions in terms of water and nutrient uptake, anchorage to the soil and the establishment of biotic interactions at the rhizosphere. Phenotyping and identifying root traits and their genes or QTLs are required in crop improvement programs to develop cultivars with root systems for efficient resource capture and improved adaptation to edaphic stresses. To achieve sustainable crop production, it is also important to maximise root adaptation and aboveground physiological functions by integrating appropriate agronomic practices and rhizosphere interactions.

Acknowledgements We thank the Editor-in-Chief Hans Lambers, the Managing Editor Lieve Bultynck, and journal editorial team for their encouragements and support in the course of preparing this special issue. The assistance of Section Editors Felipe E. Albornoz, Ian Dodd, Tatsuhiro Ezawa, Tim S. George, John Hammond, Rafael S. Oliveira, Martin Weih, and W. Richard Whalley at Plant and Soil for the editing some of manuscripts are gratefully acknowledged. Northwest A\&F University, The University of Western Australia, China State Administration of Foreign Experts Affairs' "111" Program (B12007), National Natural Science Foundation of China (31471946), and Chinese Academy of Sciences "100 Talent" Program (A315021449), provided financial support for the organisation of this International Symposium on Crop Roots and Rhizosphere Interactions (9-13 October, 2017, Yangling, China).

\section{References}

Abdolshahi R, Nazari M, Safarian A, Sadathossini TS, Salarpour M, Amiri H (2015) Integrated selection criteria for drought tolerance in wheat (Triticum aestivum L.) breeding programs using discriminant analysis. Field Crop Res 174:20-29

Adiku SG, Ozier-Lafontaine H, Bajazet T (2001) Patterns of root growth and water uptake of a maize-cowpea mixture grown under greenhouse conditions. Plant Soil 235:85-94

Barea JM, Pozo MJ, Azcon R, Azcon-Aguilar C (2005) Microbial co-operation in the rhizosphere. J Exp Bot 56:1761-1778

Chen Y, Dunbabin VM, Diggle AJ, Siddique KHM, Rengel Z (2011) Development of a novel semi-hydroponic phenotyping system for studying root architecture. Funct Plant Biol 38:355-363

Chen Y, Dunbabin VM, Diggle AJ, Siddique KHM, Rengel Z (2012) Assessing variability in root parameters of wild Lupinus angustifolius germplasm: basis for modelling root system structure. Plant Soil 354:141-155

Chen Y, Palta J, Clements J, Buirchell B, Siddique KHM, Rengel Z (2014) Root architecture alteration of narrow-leafed lupin and wheat in response to soil compaction. Field Crop Res $165: 61-70$
Chen Y, Ghanem ME, Siddique KHM (2017) Characterising root trait variability in chickpea (Cicer arietinum L.) germplasm. J Exp Bot 68:1987-1999

Djanaguiraman M, Prasad PVV, Kumari J, Rengel Z (2019) Root length and root lipid composition contribute to drought tolerance of winter and spring wheat. Plant Soil. https://doi. org/10.1007/s11104-018-3794-3

Dunbabin VM, Postma J, Schnepf A, Pagès L, Javaux M, Wu L, Leitner D, Chen Y, Rengel Z, Diggle AJ (2013) Modelling root-soil interactions using three-dimensional models of root growth, architecture and function. Plant Soil 372:93-124

Gregory PJ, Bengough AG, Grinev D, Schmidt S, Thomas WB, Wojciechowski T, Young IM (2009) Root phenomics of crops: opportunities and challenges. Funct Plant Biol 36: 922-929

Hecht VL, Temperton VM, Nagel KA, Rascher U, Pude R, Postma JA (2019) Plant density modifies root system architecture in spring barley (Hordeum vulgare L.) through a change in nodal root number. Plant Soil. https://doi. org/10.1007/s11104-018-3764-9

Heřmanská A, Středa T, Chloupek O (2015) Improved wheat grain yield by a new method of root selection. Agron Sustain Dev 35:195-202

Houle D, Govindaraju DR, Omholt S (2010) Phenomics: the next challenge. Nat Rev Genet 11:855-866

Lambers H, Shane MW, Cramer MD, Pearse SJ, Veneklaas EJ (2006) Root structure and functioning for ef fi cient acquisition of phosphorus: matching morphological and physiological traits. Ann Bot 98:693-713

Li X, He C, He X, Su F, Hou L, Ren Y, Hou Y (2019a) Dark septate endophytes improve the growth of host and non-host plants under drought stress through altered root development. Plant Soil. https://doi.org/10.1007/s11104-019-04057-2

Li C, Kuyper TW, van der Werf W, Zhang J, Li H, Zhang F, Hoffland E (2019b) Testing for complementarity in phosphorus resource use by mixtures of crop species. Plant Soil. https://doi.org/10.1007/s11104-018-3732-4

Li H, Wang X, Brooker RW, Rengel Z, Zhang F, Davies WJ, Shen $J$ (2019c) Root competition resulting from spatial variation in nutrient distribution elicits decreasing maize yield at high planting density. Plant Soil. https://doi.org/10.1007/s11104018-3812-5

Li S, Wang W, Cao Y, Wang C, Yan C, Dong L, Wu L, Xie F, Song S (2019d) How root traits would be affected by soybean yield improvement? An examination of historical cultivars grafted with record-yield cultivar scion. Plant Soil. https://doi. org/10.1007/s11104-018-3792-5

Liu W, Zou J, Zhang J, Yang F, Wan Y, Yang W (2015) Evaluation of soybean (Glycine max) stem vining in maize-soybean relay strip intercropping system. Plant Product Sci 18:69-75

Lynch JP (2013) Steep, cheap and deep: an ideotype to optimize water and $\mathrm{N}$ acquisition by maize root systems. Ann Bot 12: 347-357

Lynch JP, Brown KM (2012) New roots for agriculture: exploiting the root phenome. Philos Trans R Soc B: Biol Sci 367:1598-1604

Ma L, Li Y, Wu P, Zhao X, Chen X, Gao X (2019) Effects of varied water regimes on root development and its relations with soil water under wheat/maize intercropping system. Plant Soil. https://doi.org/10.1007/s11104-018-3800-9

Mai TH, Schnepf A, Vereecken H, Vanderborght J (2019) Continuum multiscale model of root water and nutrient 
uptake from soil with explicit consideration of the 3D root architecture and the rhizosphere. Plant Soil. https://doi. org/10.1007/s11104-018-3890-4

Malamy JE (2005) Intrinsic and environmental response pathways that regulate root system architecture. Plant Cell Environ 28: $67-77$

Manschadi AM, Christopher J, Hammer GL (2006) The role of root architectural traits in adaptation of wheat to waterlimited environments. Funct Plant Biol 33:823-837

Meister R, Rajani MS, Ruzicka D, Schachtman DP (2014) Challenges of modifying root traits in crops for agriculture. Trends Plant Sci 19:779-788

Palta JA, Turner NC (2019) Crop root system traits cannot be seen as a silver bullet delivering drought resistance. Plant Soil. https://doi.org/10.1007/s11104-018-3864-6

Qiao S, Fang Y, Wu A, Xu B, Zhang S, Deng X, Djalovic I, Siddique KHM, Chen Y (2019) Dissecting root trait variability in maize genotypes using the semi-hydroponic phenotyping platform. Plant Soil. https://doi.org/10.1007/s11104-018-3803-6

Qin X, Feng F, Wen X, Siddique KHM, Liao Y (2019a) Historical genetic responses of yield and root traits in winter wheat in the yellow-Huai-Hai River valley region of China due to modern breeding (1948-2012). Plant Soil. https://doi. org/10.1007/s11104-018-3832-1

Qin X, Li Y, Shi C, Song D, Wen X, Liao Y, Siddique KHM (2019b) The number of cultivars in varietal winter-wheat mixtures influence aboveground biomass and grain yield in North China. Plant Soil. https://doi.org/10.1007/s11104-019-04084-z

Reynolds MP, Pierre CS, Saad AS, Vargas M, Condon AG (2007) Evaluating potential genetic gains in wheat associated with stress-adaptive trait expression in elite genetic resources under drought and heat stress. Crop Sci 47:S172

Shane MW, Lambers H (2005) Cluster roots: a curiosity in context. Plant Soil 274:101-125

Shao H, Shi D, Shi W, Ban X, Chen Y, Ren W, Chen F, Mi G (2019) Genotypic difference in the plasticity of root system architecture of field-grown maize in response to plant density. Plant Soil. https://doi.org/10.1007/s11104-019-03964-8

Siddique KH, Belford RK, Tennant D (1990) Root: shoot ratios of old and modern, tall and semi-dwarf wheats in a Mediterranean environment. Plant Soil 121:89-98
Sun B, Gao Y, Yang H, Zhang W, Li Z (2019) Performance of alfalfa rather than maize stimulates system phosphorus uptake and overyielding of maize/alfalfa intercropping via changes in soil water balance and root morphology and distribution in a light chernozemic soil. Plant Soil. https://doi.org/10.1007/s11104-018-3888-y

Turner NC (2019) Imposing and maintaining soil water deficits in drought studies in pots. Plant Soil. https://doi.org/10.1007 /s11104-018-3893-1

Waines JG, Ehdaie B (2007) Domestication and crop physiology: roots of green-revolution wheat. Ann Bot 100:991-998

Wang X, Ding W, Lambers H (2019a) Nodulation promotes cluster-root formation in Lupinus albus under low phosphorus conditions. Plant Soil. https://doi.org/10.1007/s11104018-3638-1

Wang W, Ding GD, White PJ, Wang XH, Jin KO, Xu FS, Shi L (2019b) Mapping and cloning of quantitative trait loci for phosphorus efficiency in crops: opportunities and challenges. Plant Soil. https://doi.org/10.1007/s11104-018-3706-6

Xiang C, Ren J, Zhao XQ, Ding ZS, Zhang J, Wang C, Zhang JW, Joseph CA, Zhang Q, Pang YL, Gao YM, Shi YY (2015) Genetic dissection of low phosphorus tolerance related traits using selected introgression lines in rice. Rice Sci 22:264-274

Xie W, Hao Z, Yu M, Wu Z, Zhao A, Li J, Zhang X, Chen B (2019) Improved phosphorus nutrition by arbuscular mycorrhizal symbiosis as a key factor facilitating glycyrrhizin and liquiritin accumulation in Glycyrrhiza uralensis. Plant Soil. https://doi.org/10.1007/s11104-018-3861-9

York LM, Nord E, Lynch J (2013) Integration of root phenes for soil resource acquisition. Front Plant Sci 4:355

Zhan A, Schneider H, Lynch JP (2015) Reduced lateral root branching density improves drought tolerance in maize. Plant Physiol 168:1603-1615

Zhu J, Ingram PA, Benfey PN, Elich T (2011) From lab to field, new approaches to phenotyping root system architecture. Curr Opin Plant Biol 14:310-317

Publisher's note Springer Nature remains neutral with regard to jurisdictional claims in published maps and institutional affiliations. 